Research Article

\title{
Numerical Study on the Impact Instability Characteristics Induced by Mine Earthquake and the Support Scheme of Roadway
}

\author{
Guang-jian Liu $\mathbb{D}^{1,2}$ Shan-lin Li ${ }^{10},{ }^{1}$ Zong-long Mu $\mathbb{D}^{2},{ }^{2}$ Wen Chen $\mathbb{D D}^{3}$ Lei-bo Song $\mathbb{D}^{1}{ }^{1}$ \\ Jie Liu $\mathbb{D}^{1}{ }^{1}$ and Yu-dong $X u \mathbb{D}^{1}$ \\ ${ }^{1}$ Key Laboratory of Rock Mechanics and Geohazards of Zhejiang Province, Shaoxing University, Shaoxing, \\ Zhejiang 312099, China \\ ${ }^{2}$ Jiangsu Engineering Laboratory of Mine Earthquake Monitoring and Prevention, China University of Mining and Technology, \\ Xuzhou, Jiangsu 221116, China \\ ${ }^{3}$ School of Transportation and Civil Engineering, Nantong University, Nantong, Jiangsu 226000, China \\ Correspondence should be addressed to Lei-bo Song; song_leibo@163.com
}

Received 27 July 2021; Revised 19 August 2021; Accepted 26 August 2021; Published 13 September 2021

Academic Editor: Fan Deyuan

Copyright (C) 2021 Guang-jian Liu et al. This is an open access article distributed under the Creative Commons Attribution License, which permits unrestricted use, distribution, and reproduction in any medium, provided the original work is properly cited.

\begin{abstract}
Rockburst of deep roadway was induced by the superposition of mine earthquake disturbance and high static stress exceeding the limit strength of coal-rock mass. To study the roadway impact instability characteristics caused by mine earthquake disturbance and to propose an optimized support scheme, the discrete element model of the roadway structure was established based on the 1305 working face of the Zhaolou Coal Mine. The influence of mine earthquake amplitude and hypocenter location on the roadway was analyzed. The mesocrack evolution characteristics of the roadway were simulated and reproduced. Characteristics of stress field, crack field, displacement field, and energy field of the disturbed roadway with different support schemes were studied. The results showed that the greater the amplitude of the mine earthquake was, the severer the roadway impact failure was. The upper and left hypocenters had a significant influence on the roadway. The superposition of the high static stress and the dynamic stress due to the far-field mine earthquake resulted in the impact instability of coal-rock mass around the roadway, causing severe roof subsidence as well as rib and bottom heave. The evolution of tensile cracks caused the severe impact failure of roadway from a mesoscopic perspective. Using the flexible support to reinforce the roadway retarded the stress decline in roof and rib, improved the self-stability, reduced the number of near-field cracks, and decreased the displacement. Meanwhile, it allowed the roof and rib deformation, which was conducive to releasing elastic energy in surrounding rocks and reducing mine earthquake energy. The cracks and deformation in the floor were controlled by using the floor bolt. The optimal support scheme for a roadway to resist mine earthquake disturbance was proposed: "bolt-cable-meshsteel strip- $\pi$-beam + floor bolt." The research results have a specific guiding significance for the support of the coal mine roadway.
\end{abstract}

\section{Introduction}

With the increasing depth and strength of coal mining, a growing number of rockburst mines appear. The frequency and intensity of rockburst were aggrandized year by year [1-3]. Rockburst is a dynamic disaster caused by the sudden release of elastic potential energy in coal-rock mass during coal mining. According to the statistics, 90 percent of rockburst disasters happen in mining roadways [4-6]. The roadway impact instability is mainly induced by the superposition of high static stress and high-energy mine earthquake.
In recent years, diverse methods have been widely utilized to investigate the impact instability characteristics of roadway. Adopting theoretical calculation, the attenuated and dissipative rules of mine earthquake energy were analyzed during the propagation process [7-9], and the deformation and crack development characteristics of the roadway were obtained $[10,11]$. The mechanism on roadway impact instability induced by high stress and mine earthquake was researched by laboratory test [12-14]. The results obtained from the field test are reliable due to its real stress conditions. In Xiao et al.'s opinion [15], the development of sliding rockburst began with several tensile failure events; 
afterward, the shear, mixing, and tensile failure events occurred alternately. Compared with other research methods, the numerical method has many advantages such as low cost, high efficiency, and repeatability, especially in the research on the failure mechanism of the roadway. Li and Weng [16] found strain energy density (SED) characteristics and investigated fracturing zone under various lateral pressure coefficients in the numerical simulation. Panthi [17] supposed that the effect of rockburst depended on the maximum tangential stress, rock brittleness, and rock strength. Zhu et al. [18] believed that the dynamic disturbance triggering the rockburst is closely dependent on the static geostress condition. Liu et al. [19] explained that the rapid and massive release of elastic energy induced the dynamic rupture in the floor. Liu et al. [20, 21] studied the failure evolution and instability mechanism of surrounding rock.

Many scholars have also focused on preventing roadway impact instability by improving support schemes. The bolt and cable were often adopted to strengthen the surrounding rock. Kang [22] believes that the essential effect of bolt support on the deformation of rockburst roadway is to maintain the integrity of surrounding rock, reduce the stress concentration coefficient, and improve the stress distribution of surrounding rock of roadway. Jing et al. [23] and Xiao et al. [24] proposed the support principle to strengthen the integrity and loading capacity of the surrounding rock and control roadway impact instability. Another frequently used technique is the mesh support. The mesh significantly reduced the acceleration magnitude of the supported roadway section [25]. Moreover, the rigid support had an excellent function in preventing the deformation of the roadway. $\mathrm{Su}$ et al. [26] conducted UDEC simulations to analyze the bearing characteristics and deformation and failure characteristics of surrounding layered rock in the deep roadway. Li et al. [27] proposed the support scheme "bolt-meshshotcrete + square arch." Yu et al. [28] and Yang et al. [29] improved the rigid support according to the deformation characteristics of roadway. However, from Peter and Cai's view [30], support in rockburst-prone areas must be able to absorb dynamic energy and adapt to sizeable sudden rock deformation due to rockburst and related expansion. Under his influence, Yang et al. [31] proposed that the activeflexible support can increase the confining pressure of surrounding rock to suppress the tensile stress state of surrounding rock. Jiao et al. [32] proposed the support method "metal mesh plus backfilled chemical grouting material plus double resistant geomembrane plus U-shaped steel." Finally, Sun et al. [33] considered that the technology of "bolt-net-spray + anchor cable + floor bolt" asymmetric coupling support can significantly reduce the deformation in the key area of the surrounding rock mass of the roadway.

In conclusion, the literature usually focuses on the macrofeature of mine earthquake-induced roadway impact instability and ignores the mesofeature, resulting in the inaccurate and incomplete description of roadway impact instability mechanism. Moreover, the influence of the mine earthquake on roadway support has been neglected, causing the waste of supporting materials and the nonideal control effect of roadway impact instability. This paper aims to study the characteristics of roadway impact instability induced by mine earthquake disturbance and propose an optimized support scheme.

\section{Research Background}

Zhaolou Coal Mine is located in Heze City, Shandong Province, China. The 1305 island working face mining depth in the No. 1 mining area is $960-1000 \mathrm{~m}$. The roadway is in a high static stress state. The overlying roof strata continue to break and fall due to the near goaf, resulting in a large number of mine earthquakes, which has a significant impact on the 1305 working face.

The main coal seam in the 1305 working face is $3 \#$, with an average thickness of $8.2 \mathrm{~m}$. The borehole column is shown in Figure 1. The roof is mudstone with a thickness of $4.1 \mathrm{~m}$, medium sandstone with a thickness of $6.1 \mathrm{~m}$, and fine sandstone with a thickness of $6.5 \mathrm{~m}$. The floor is mudstone with a thickness of $8.3 \mathrm{~m}$ and sandstone with a thickness of $6.1 \mathrm{~m}$, respectively.

From July 15 to August 15, 2015, the location distribution of the mine earthquake in the 1305 working face is illustrated in Figure 2. It can be found that the mine earthquake hypocenter was concentrated in the overlying roof strata. Figure 3 illustrates the field situation of roadway impact instability in the 1305 working face. The statistics of mine earthquake energy are shown in Table $1.80 \%$ of the mine earthquake ranges from 100 to $1000 \mathrm{~J}$, and the maximum energy can reach $2.26 \times 10^{6} \mathrm{~J}$, located in the roof sandstone.

\section{Numerical Simulation Model}

3.1. Correction of Mechanical Parameters. The natural rock mass comprises different mineral components. It contains joints, cracks, bedding, and other structures, so the rock mass presents heterogeneity and discontinuity, resulting in an apparent deficiency of continuum mechanics. Compared with the finite element method, the discrete element method can replicate the failure mode and strong nonlinear mechanical phenomena of surrounding rock of deep roadway. It can also better simulate the fracture, movement, and extensive deformation process of the roadway and reveal the failure process of the roadway.

In this paper, the block discrete element software UDEC was used to study the failure mechanism and support mode of the roadway under mine earthquake. The elastic model was assigned to the blocks to avoid possible failures in discrete elements. The Coulomb slip model was set at the contact surface to simulate crack sliding or opening. The tensile or shear failure can be evaluated according to the stress state. The numerical model was established according to the borehole column of 1305 working face of the Zhaolou Coal Mine, which was composed of coal, mudstone, and sandstone. In addition, the parameters of roadway were referred to that in 1305 working face. To calibrate the mesomechanical parameters, the uniaxial compression and Brazilian tests were conducted on a $50 \mathrm{~mm} \times 100 \mathrm{~mm}$ 


\begin{tabular}{|c|c|c|c|}
\hline Lithology name & $\begin{array}{l}\text { Geological } \\
\text { Formations }\end{array}$ & Depth (m) & Thickness (m) \\
\hline $\begin{array}{c}\text { Fine } \\
\text { sandstone }\end{array}$ & & 862.0 & 13.5 \\
\hline Mudstone & & 875.5 & 8.8 \\
\hline $\begin{array}{c}\text { Fine } \\
\text { sandstone }\end{array}$ & & 884.3 & 6.5 \\
\hline Sandstone & & 890.8 & 6.1 \\
\hline Mudstone & & 896.9 & 4.1 \\
\hline 3\# Coal & & 901.0 & 8.2 \\
\hline Mudstone & & 909.3 & 8.3 \\
\hline Sandstone & & 915.4 & 6.1 \\
\hline Mudstone & & 923.6 & 8.2 \\
\hline
\end{tabular}

Figure 1: The borehole column in the 1305 working face.

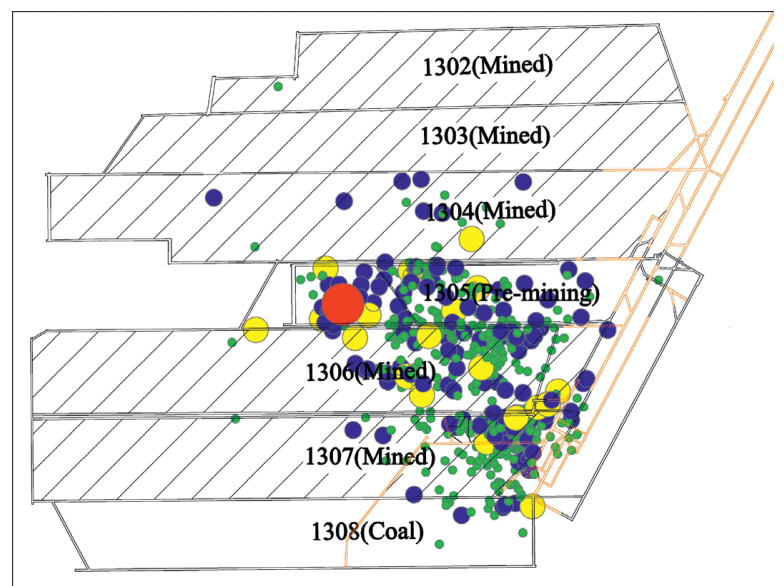

(a)

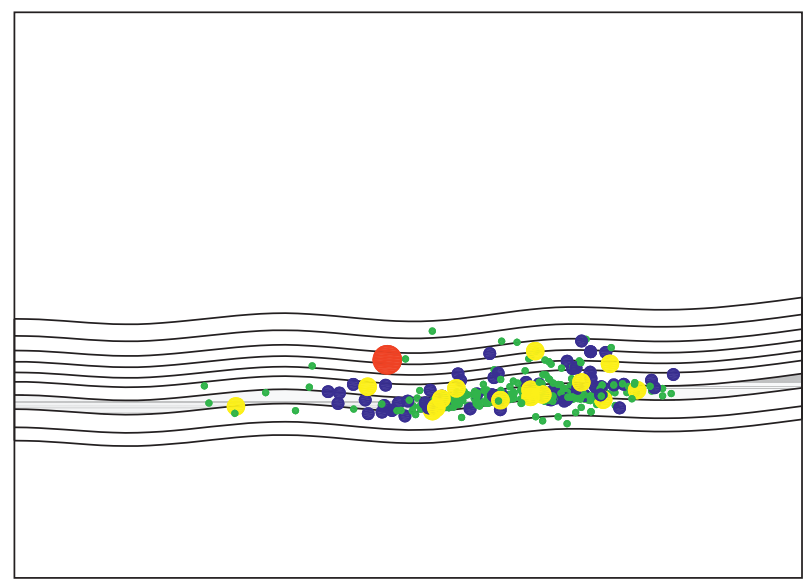

(b)

Figure 2: Hypocenter distribution. (a) Plan view. (b) Section view.

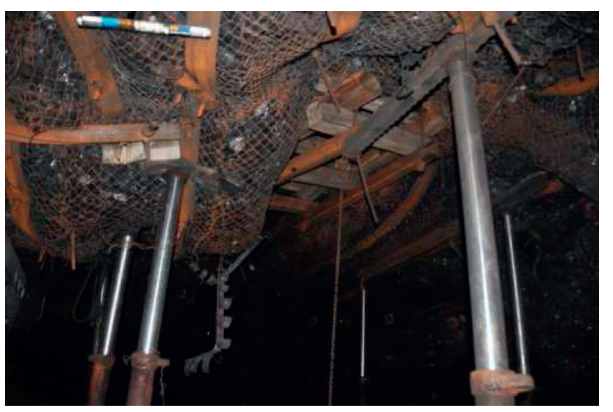

(a)

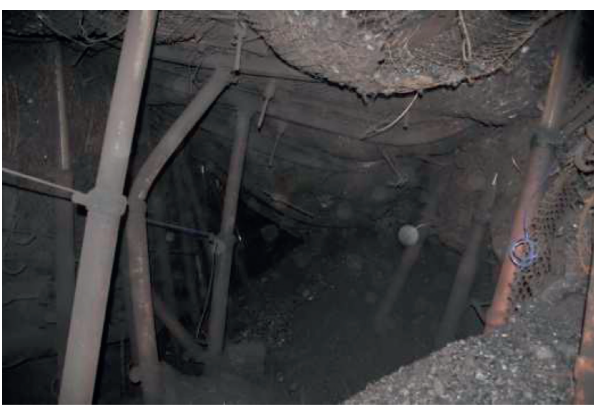

(b)

FIGURE 3: The figures of roadway impact instability in the 1305 working face. (a) Roof caving. (b) Roadway deformation. 
TABLE 1: Mine earthquake energy statistics in the 1305 working face.

\begin{tabular}{lcc}
\hline Energy classification $(\mathrm{J})$ & Frequency & Percent $(\%)$ \\
\hline $10^{2} \sim 10^{3}$ & 389 & 80.37 \\
$10^{3} \sim 10^{4}$ & 76 & 15.7 \\
$10^{4} \sim 10^{5}$ & 18 & 3.72 \\
$>10^{5}$ & 1 & 0.21 \\
\hline
\end{tabular}

cylindrical sample and a Brazilian disc with a diameter of $50 \mathrm{~mm}$ [34-36].

The elastic modulus $E$ and Poisson's ratio $v$ of the models were determined based on the stress and strain values obtained from the mechanical tests. The bulk modulus and shear modulus of rock blocks were calculated according to the elastic modulus and Poisson's ratio of rock materials. The calculation formulas of bulk modulus and shear modulus are as follows:

$$
\begin{aligned}
& K=\frac{E}{3(1-2 \nu)}, \\
& G=\frac{E}{2(1+\nu)},
\end{aligned}
$$

where $K$ is the bulk modulus, $G$ is the shear modulus, $E$ is elastic modulus, and $v$ is Poisson's ratio.

The normal stiffness and shear stiffness of joints are usually less than ten times the equivalent stiffness of adjacent elements of joints. The calculation formulas of normal stiffness and shear stiffness of joints are as follows:

$$
\begin{aligned}
& k_{n} \leq 10\left[\max \frac{K+(4 / 3) G}{\Delta Z_{\min }}\right], \\
& k_{s}=0.4 \times k_{n},
\end{aligned}
$$

where $\Delta Z_{\text {min }}$ is the minimum width of the adjacent joint element in normal direction. The value $\left(k_{s} / k_{n}\right)$ is calibrated by the Poisson ratio. $\Delta Z_{\min }$ is determined by the maximum edge length $V$ of a triangular element defined in the command GEN edge $V$.

The mechanical parameters of internal friction angle $\varphi$, cohesive force $C$, and tensile strength $\sigma_{t}$ were obtained or back-calculated from the uniaxial compression and Brazilian tests. The multistage parametric analysis was taken to calibrate the parameters. The simulation results obtained from the uniaxial compression and Brazilian tests were compared to the macroscopic mechanical parameters (compressive strength, elastic modulus, etc.) coal-rock mass, as illustrated in Figure 4. The calibrated mechanical parameters of blocks and joints are shown in Tables 2 and 3.

3.2. Roadway Model and Simulation Scheme. A roadway numerical model with a size of $34 \mathrm{~m}$ (width) $\times 32 \mathrm{~m}$ (height) was established, as illustrated in Figure 5(a), and the block was divided into several discrete triangular blocks by the UDEC-Trigon method. Small triangle blocks with an average side length of smaller than $0.5 \mathrm{~m}$ were generated near the model roadway, which was beneficial to study the failure mode of roadway surrounding rock. The remaining triangular blocks with an average size of $0.8 \mathrm{~m}$ were used to improve the computational efficiency. The horizontal displacement of the left and right boundary was constrained in the $x$-direction. Both the $x$-direction and $y$-direction of the bottom edge were fixed. The vertical stress was applied at the top boundary to simulate the pressure of the overlying strata. The monitoring points were arranged around the roadway by FISH code. Nineteen monitoring points with the interval of $0.3 \mathrm{~min}$ the roof and floor were set to record the vertical displacement. Similarly, 13 monitoring points in the rib recorded the horizontal displacement. The mine earthquake was applied on the top boundary and superimposed on the static stress. The seismic waveform is shown in Figure 5(b) (in the case of the $60 \mathrm{MPa}$ amplitude).

3.3. Damping Setting. In the dynamic response analysis of rock mass, the purpose of setting damping was to simulate the actual energy attenuation process of the rock-joint system. In a geotechnical medium, the natural attenuation of energy had a lag effect called frequency correlation. However, the propagation process of the shock wave was very complex due to its reflection, refraction, diffraction, and superposition in the jointed rock mass, as well as the influence of loading mode and path. As a result, it was challenging to accurately simulate the damping effect in rock mass when using numerical calculation. The damping value was generally determined by repeated trial calculation and comparison with the known measured results.

Two parameters were necessary when using Rayleigh damping in UDEC: the critical damping ratio $\xi_{\text {cr }}$ and the center frequency of rock vibration $f$. In the simulation analysis, $\xi_{\mathrm{cr}}$ was determined to be $5 \%$ by calculation. The natural frequency of jointed rock mass could be estimated by equation (3), about $5 \mathrm{~Hz}$ [37].

$$
f=\frac{1}{2 \pi}\left(\frac{k l}{m}\right)^{1 / 2},
$$

where $l$ is the joint length, $0.5 \mathrm{~m}$; $k$ is the joint stiffness, $152 \mathrm{GPa} . m$ is the mass of rock within the scope of calculation model $(\mathrm{kg})$.

\section{Impact Instability Characteristics of Roadway with Mine Earthquake Disturbance}

The mine earthquake is induced by the sudden release of energy accumulated in the surrounding rock. The reason for energy release is that the mining area and roadway stresses are in an unstable state, which is affected by mining activities. Indirectly, mining unloading induces mine earthquake, which means that it is generated by rock fracture and strain energy due to stress concentration.

4.1. Amplitude of Mine Earthquake. Mine earthquakes with different amplitude were generated by rock fracture due to the difference in the ability to accumulate the energy of surrounding rock. It was essential to study the influence of 

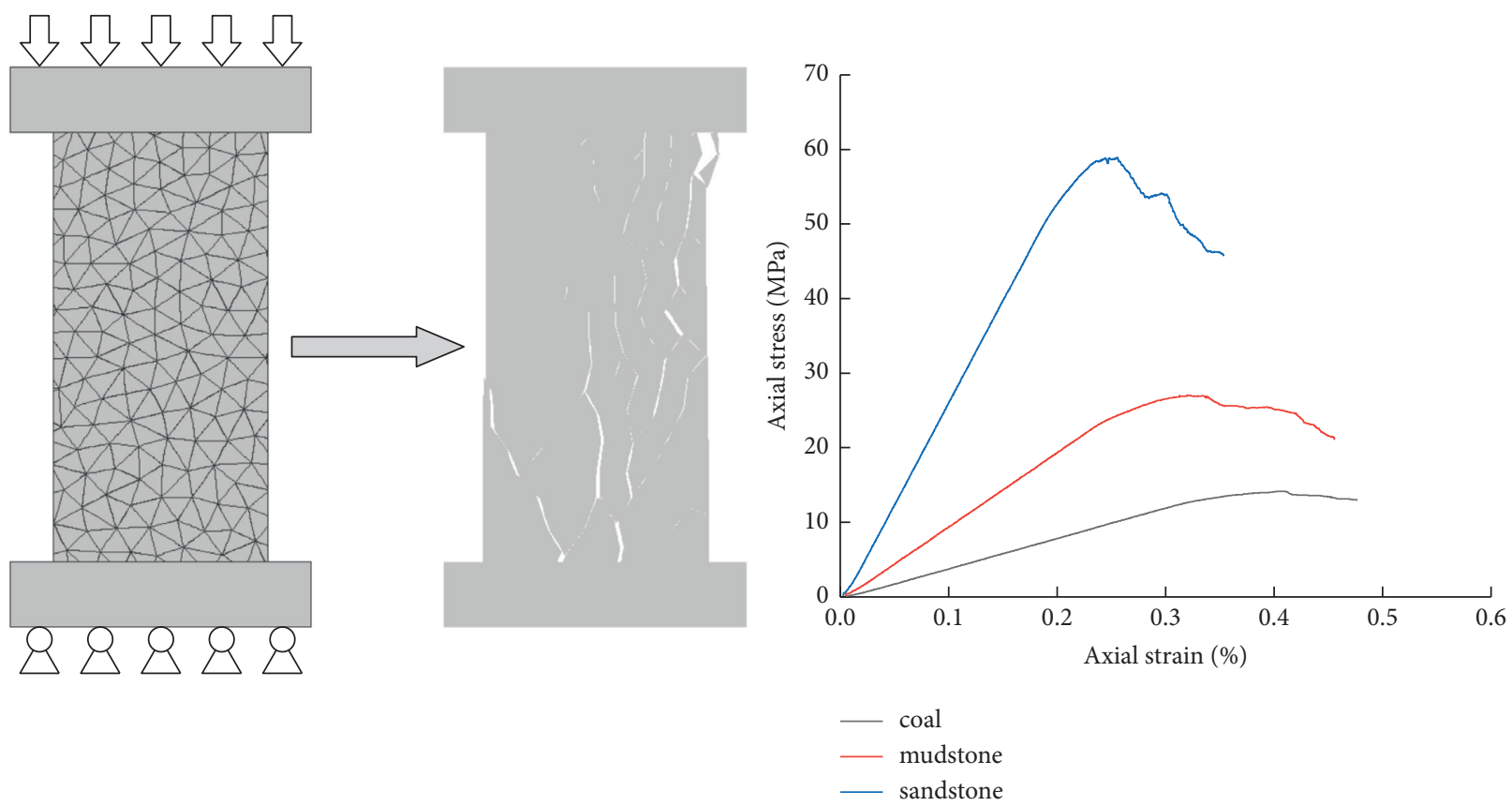

FIgURE 4: Calibration of mechanical parameters.

TABLe 2: Mechanical parameters of blocks.

\begin{tabular}{lccccc}
\hline Lithology name & Density $\left(\mathrm{kg} / \mathrm{m}^{3}\right)$ & Elastic modulus $(\mathrm{GPa})$ & Poisson's ratio & Bulk modulus $(\mathrm{GPa})$ & Shear modulus $(\mathrm{GPa})$ \\
\hline 3\# coal & 1400 & 3.2 & 0.32 & 2.96 & 1.21 \\
Mudstone & 2500 & 9.8 & 0.29 & 7.78 & 3.80 \\
Sandstone & 2550 & 27.5 & 0.26 & 17.6 & 10.9 \\
\hline
\end{tabular}

TABLE 3: Mechanical parameters of joints.

\begin{tabular}{lccccc}
\hline Lithology name & Normal stiffness $(\mathrm{N} / \mathrm{m})$ & Shear stiffness $(\mathrm{N} / \mathrm{m})$ & Friction angle $\left(^{\circ}\right)$ & Cohesive $(\mathrm{MPa})$ & Tension $(\mathrm{MPa})$ \\
\hline 3\# coal & 2000 & 800 & 18 & 3.0 & 1 \\
Mudstone & 3300 & 1400 & 20 & 8.2 & 3 \\
Sandstone & 7500 & 3100 & 26 & 15.8 & 6 \\
\hline
\end{tabular}

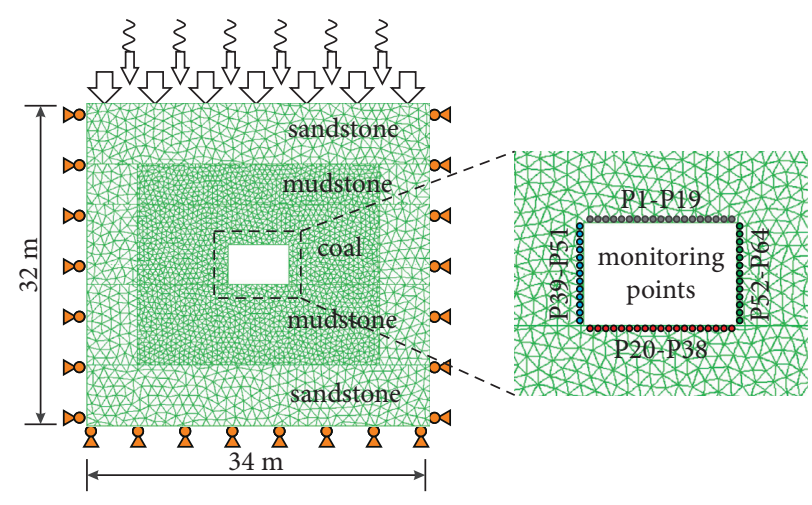

(a)

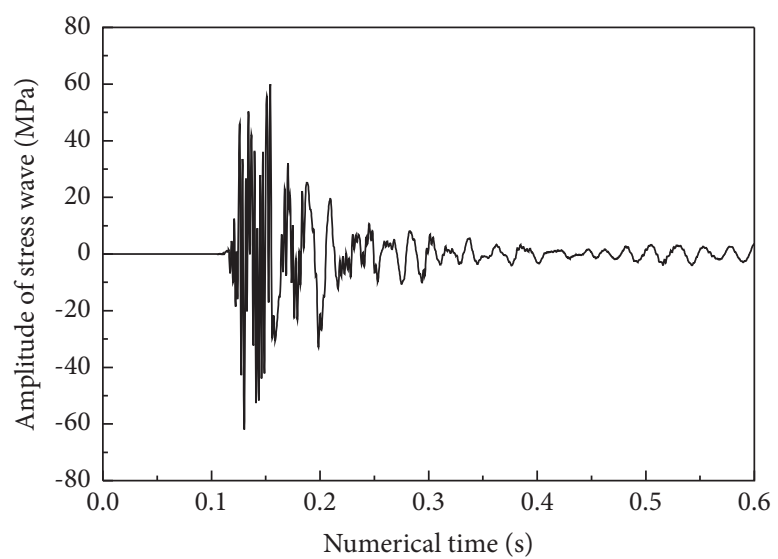

(b)

Figure 5: Numerical simulation scheme diagram of roadway. (a) Numerical model of the roadway. (b) Mine earthquake wave diagram. 
different energy of mine earthquake on roadway impact instability. According to He [38], the stress amplitude of mine earthquake with the energy of $10^{6} \mathrm{~J}$ is $60 \mathrm{MPa}$. Therefore, $0 \mathrm{MPa}, 10 \mathrm{MPa}, 20 \mathrm{MPa}, 40 \mathrm{MPa}$, and $60 \mathrm{MPa}$ mine seismic waves were applied on the upper part of 16 meters away from the roadway center. The maximum principal stress nephogram of roadway surrounding rock with different mine earthquake amplitude was obtained, as illustrated in Figure 6. The maximum principal stress in the dark blue area was about $0 \mathrm{MPa}$, which was the stress-relaxed zone, indicating that the surrounding rock was destroyed and the self-sustained ability was lost. The stress-relaxed zone of roadway extended from roof to two ribs and finally reached the bottom. The stress arch formed by the stress concentration zone spread outward. With the increase of mine earthquake amplitude, the range of the stress-relaxed zone extended. It meant that the larger the amplitude of the mine earthquake wave was, the more the energy involved in the structural damage of coal-rock mass was and the more severe the damage was.

4.2. Hypocentral Location. Due to the complex conditions in the engineering site, the mine earthquake might occur in all directions around the roadway. This will cause damage to the roadway, affecting the stability of roadway support. It was essential to study the influence of hypocentral location on roadway impact instability. In the upper, left, and bottom areas 16 meters away from the center of the roadway, seismic waves with the amplitude of $60 \mathrm{MPa}$ were applied, respectively, to obtain the displacement nephogram of the roadway surrounding rock at the different numerical time, as shown in Figure 7. When the hypocentral location was located in the upper area, the roadway roof sunk obviously, the horizontal displacement in rib was small, and the floor had no evident displacement. When the hypocenter was located in the left area, the displacement on the left side of the roadway was more extensive, the roof and floor had a slight displacement, and the displacement on the right area was the smallest. When the hypocentral location was located in the bottom area, the roadway had obvious floor heave and rib heave and slight roof subsidence. No matter where the hypocenter was found, the displacement of the corresponding side was the most obvious, and the displacement area was arched, which was mainly caused by the propagation attenuation of the mine earthquake wave and the inhibitory effect on the propagation from the roadway. The influence range of the upper earthquake hypocenter on the roadway was the widest, resulting in a large displacement of the roadway. The left hypocenter caused the most significant displacement of the roadway. The influence of the bottom hypocenter on the roadway was relatively small, indicating that the mine earthquake hypocenter on the upper and left areas had a greater impact on the roadway. Therefore, the influence of mine earthquake wave could be reduced by strengthening the support of the roof and two ribs.

4.3. Characteristics of Roadway Impact Instability. The evolution of the maximum principal stress distribution of roadway with the mine earthquake disturbance is illustrated in Figure 8. The shock wave spread circularly after the mine earthquake was applied to the model. The stress distribution of roadway changed obviously with the mine earthquake disturbance. The stress concentration area was transferred from the bottom of the roadway to the deep site. The stressrelaxed zone of roof and wall rock became arched and gradually expanded over time. When the mine earthquake action was $0.6 \mathrm{~s}$, there was a noticeable stress drop in the floor. An "elliptical" stress-relaxed zone was formed around the roadway, further destroying the stability of the surrounding rock system. Under high static stress in the roadway, the high-stress concentration further increased due to excavation. Meanwhile, the stress level of the roadway had reached its ultimate strength. The superposition of dynamic stress caused by the far-field mine earthquake and high static stress resulted in the oscillation stress in the roadway. Consequently, concentrate stress exceeded the ultimate strength of coal-rock mass, breaking the stress balance of roadway, and finally induced the impact failure of the roadway.

In order to further study the mechanism of roadway impact instability, FISH code was used to judge the failure mode of mesocracks and to track the location. The evolution of surrounding rock cracks was shown in Figure 9. When the normal tensile stress reached its tensile strength, the joint was marked as a tensile crack. When the shear stress reached its shear strength, the joint was marked as a shear crack. The shear cracks of the roadway expanded, and some shear cracks gradually transformed to tensile cracks in the influence of mine earthquake disturbance. Comparing Figure 9 to Figure 8, it can be seen that there was a specific coupling relationship between the crack propagation of roadway and the maximum principal stress, and the tensile crack area was formed. The maximum principal stress was nearly $0 \mathrm{MPa}$, leading to the loss of self-sustained ability. It was shown that the evolution of tensile cracks caused the severe impact failure of the roadway.

To find a suitable support scheme for the roadway under mine earthquake disturbance, many studies were focused on the impact instability characteristics of roadway with different support schemes. FISH code was used to limit the crack monitoring area, which meant that the precondition was $5 \mathrm{~m}$ to $29 \mathrm{~m}$ in the $x$-direction, with the bottom area of $10 \mathrm{~m}$ to $14 \mathrm{~m}$, the rib area of $14 \mathrm{~m}$ to $18 \mathrm{~m}$, and the roof area of $18 \mathrm{~m}$ to $22 \mathrm{~m}$, respectively, in the $y$-direction.

The numbers of shear cracks, tensile cracks, and cumulative cracks changed with the disturbance time were obtained from statistics, as illustrated in Figure 10. The number of shear cracks and tensile cracks increased rapidly once the mine earthquake wave arrived at the roadway, indicating that the mine earthquake disturbance was the main reason for the crack propagation of the roadway. With the influence of the mine earthquake wave, a large number of shear cracks and tensile cracks began to develop and expand in the roof and then gradually formed in rib. After some time, a small number of shear cracks and tensile cracks appeared in the bottom. The variation curve of the cumulative number of cracks with disturbance time is shown in Figure 11. The number of shear cracks was more than that of 


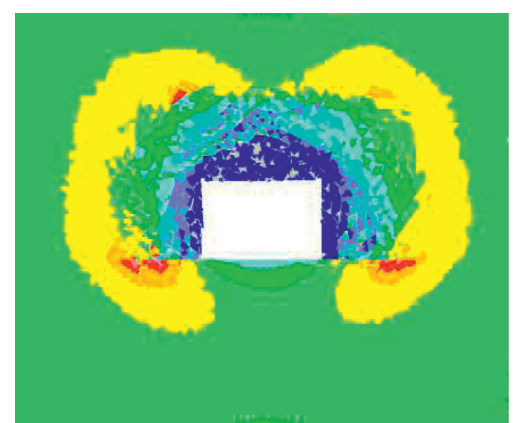

$0 \mathrm{MPa}$

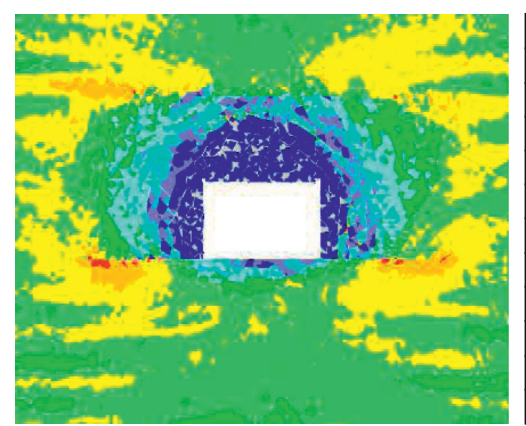

$20 \mathrm{MPa}$
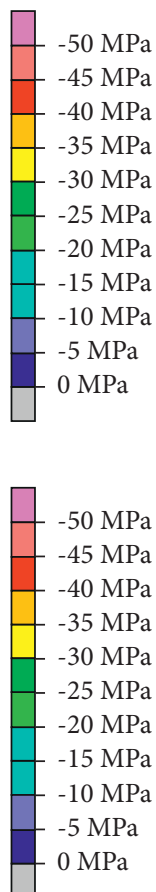

$\mathrm{MPa}$
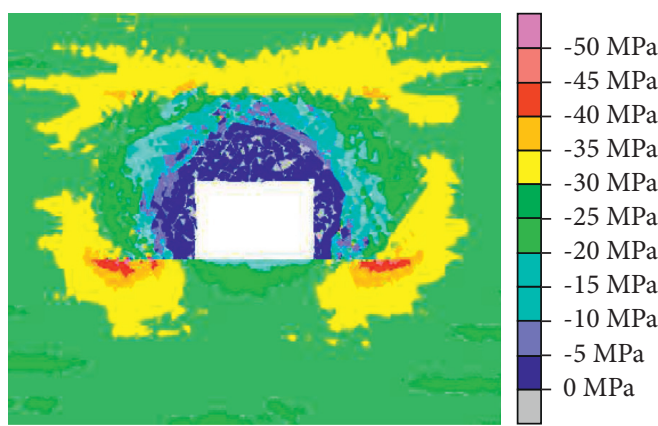

$10 \mathrm{MPa}$

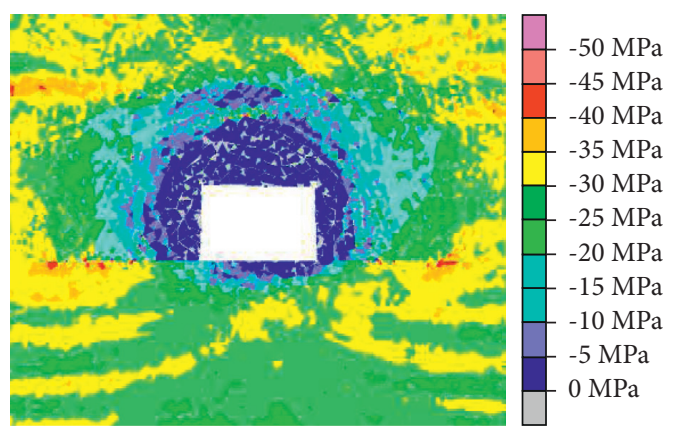

$40 \mathrm{MPa}$

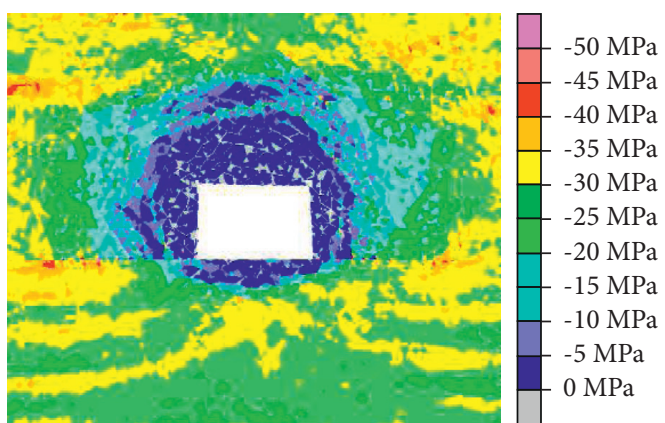

$60 \mathrm{MPa}$

FIGURE 6: Maximum principal stress distribution of roadway with different mine earthquake amplitudes.

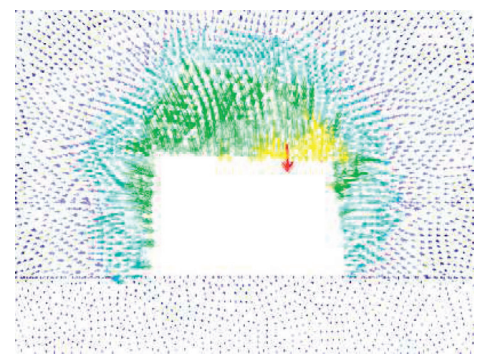

(a)
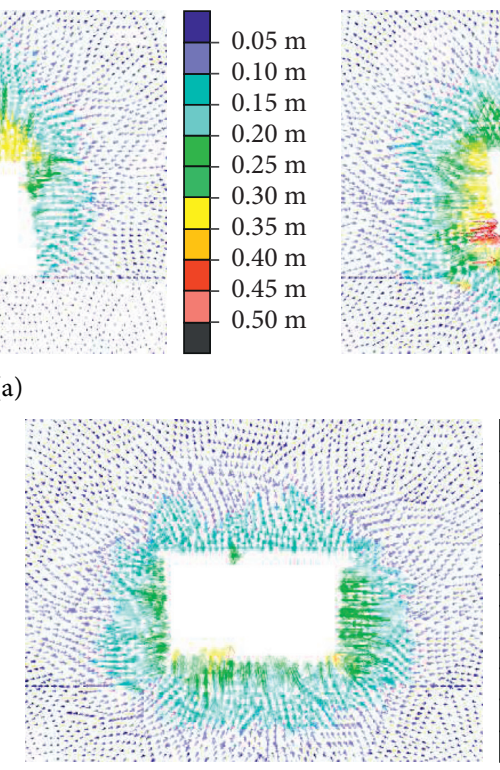

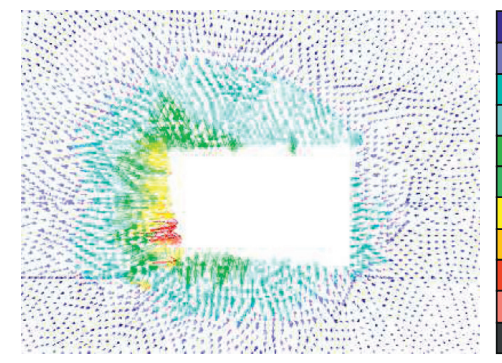

(b)

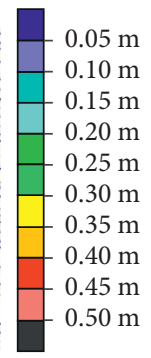

(c)

FIGURE 7: Roadway displacement nephograms with different hypocentral location. (a) Upper hypocenter. (b) Left hypocenter. (c) Bottom hypocenter. 


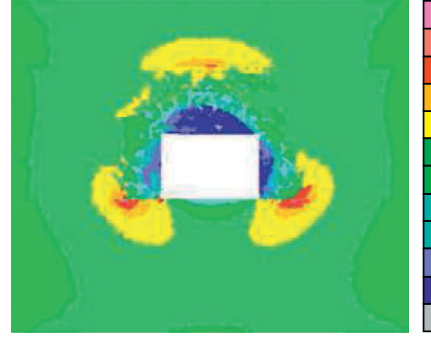

Time $=0.1 \mathrm{~s}$

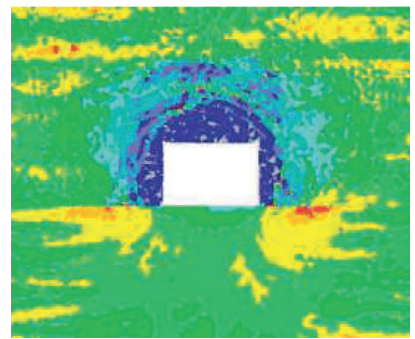

Time $=0.4 \mathrm{~s}$
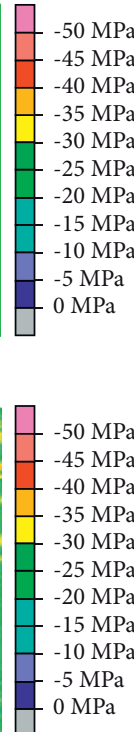

$0 \mathrm{MPa}$$$
\text { (a) }
$$

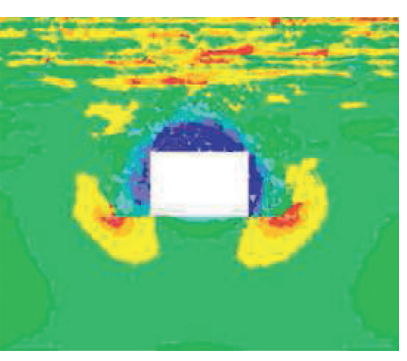

Time $=0.2 \mathrm{~s}$

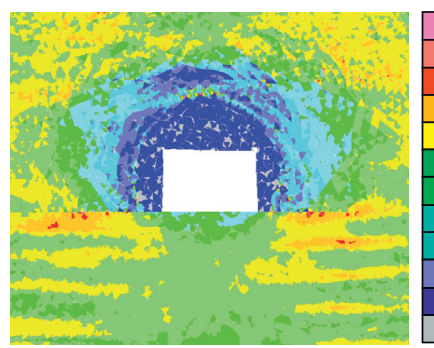

Time $=0.5 \mathrm{~s}$
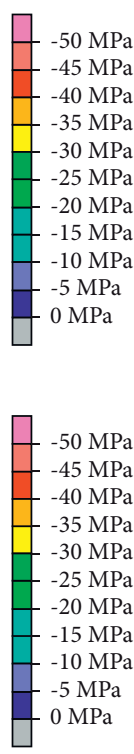

$0 \mathrm{MPa}$

Figure 8: Evolution of maximum principal stress in the surrounding rock of roadway.
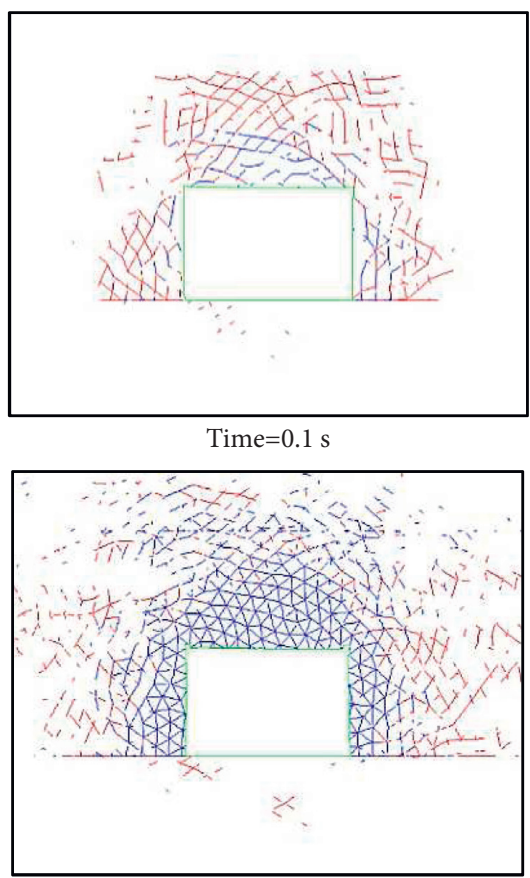

Time $=0.4 \mathrm{~s}$

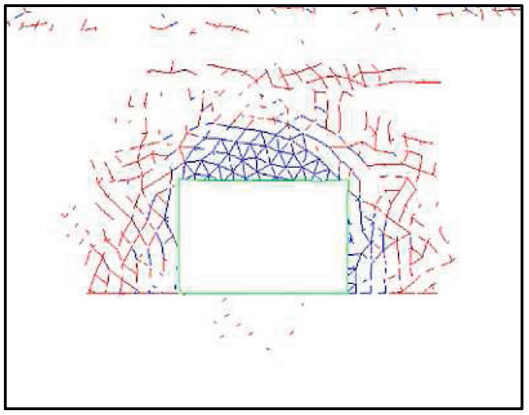

Time $=0.2 \mathrm{~s}$

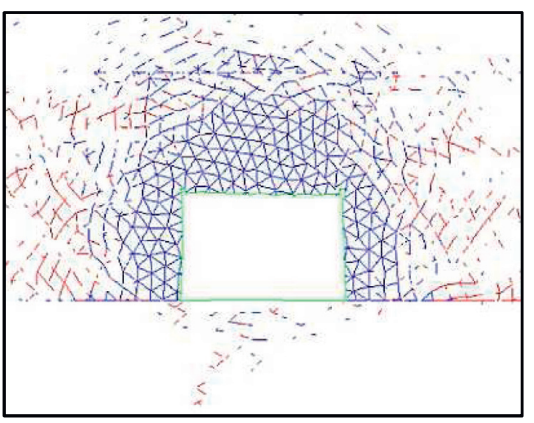

Time $=0.5 \mathrm{~s}$

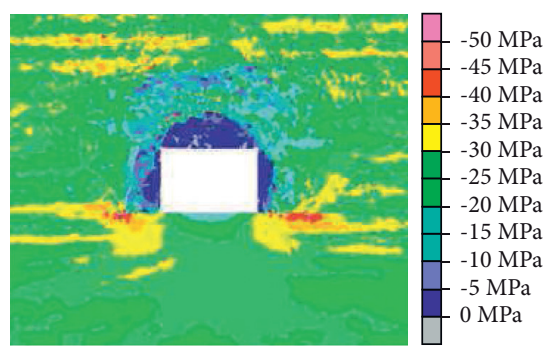

Time $=0.3 \mathrm{~s}$

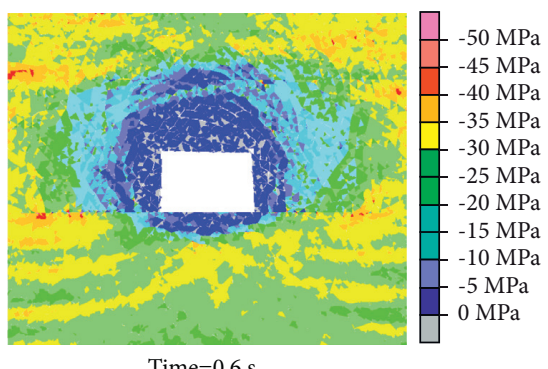

Time $=0.6 \mathrm{~s}$

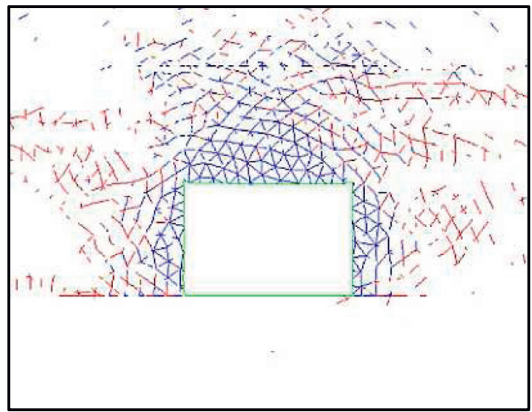

Time $=0.3 \mathrm{~s}$

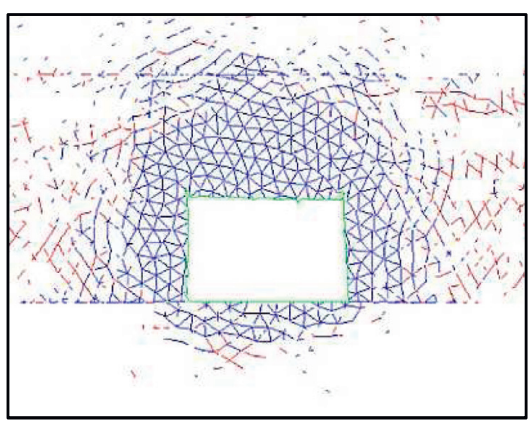

Time $=0.6 \mathrm{~s}$

Figure 9: Characteristics of mesocrack evolution (red is the shear crack, blue is the tensile crack).

tensile cracks. The shear cracks occurred earlier than tensile cracks, and some shear cracks would transform to tensile cracks. It could be concluded that the shear failures of roadway occurred along with the joint; afterward, the tensile failures occurred along with the shear failure surface under mine earthquake disturbance, resulting in the separation of fractured rock blocks and surrounding rocks and the loss of self-sustained ability.

The initiation and propagation of cracks was the root cause of roadway impact instability at the mesoscopic level, influencing the macroscopic displacement and deformation. The variation of displacement of roadway with the disturbance time of mine earthquake is illustrated in Figure 12. Monitoring points P10, P29, P45, and P58 were located at the middle points of the roadway roof, floor, left rib, and right rib, respectively. With the disturbance of the mine earthquake, the roadway displacement increased slowly at first before grown rapidly. At $0.25 \mathrm{~s}$, the slope of the displacement curve in the roof and rip increased suddenly, indicating that the surrounding rock was affected by the 

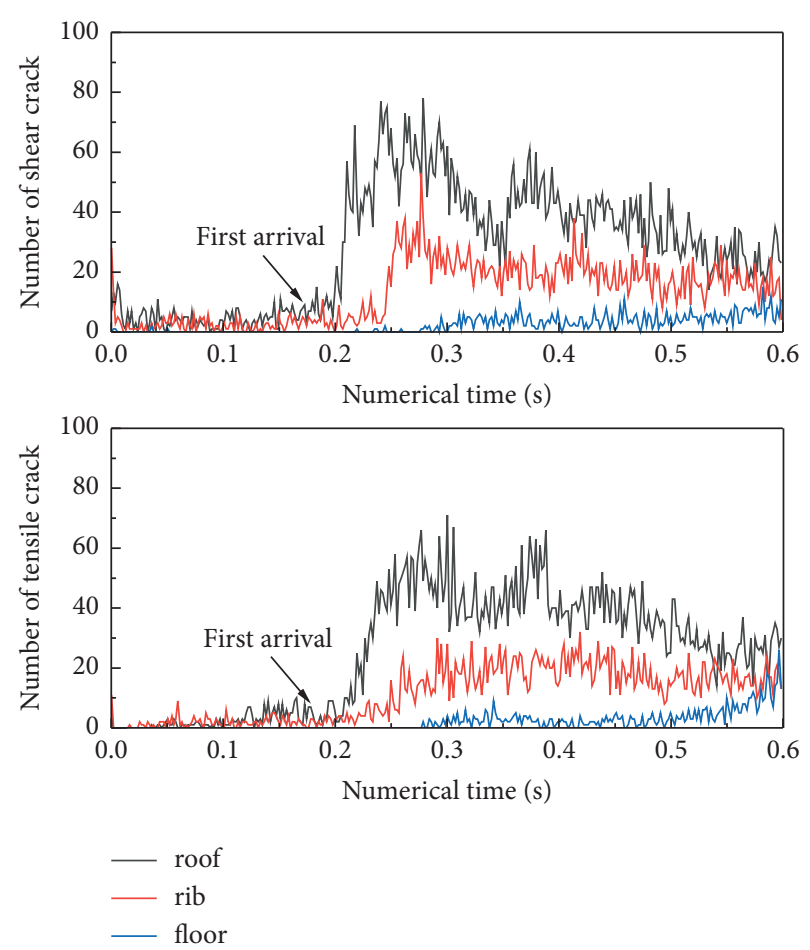

Figure 10: Variation of crack number with mine earthquake disturbance.

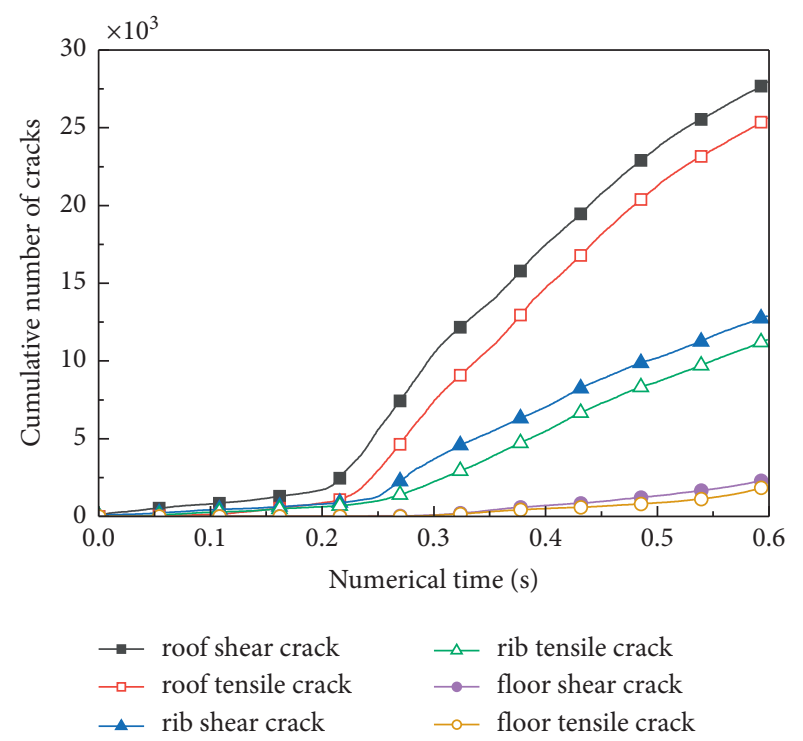

Figure 11: Variation of cumulative crack number under mine earthquake disturbance.

disturbance of the mine earthquake at this moment. The accumulated elastic deformation energy was suddenly released, resulting in a significant increase in the deformation rate of the roadway. Roadway deformation led to severe roof subsidence, rib and floor heave, and uneven surrounding rock deformation. At $0.6 \mathrm{~s}$, the displacement of the midpoint in the roof was nearly $300 \mathrm{~mm}$, those in ribs were $235 \mathrm{~mm}$ and $175 \mathrm{~mm}$, and that in the floor was about $25 \mathrm{~mm}$. The reason for the slight floor heave was that the floor lithology

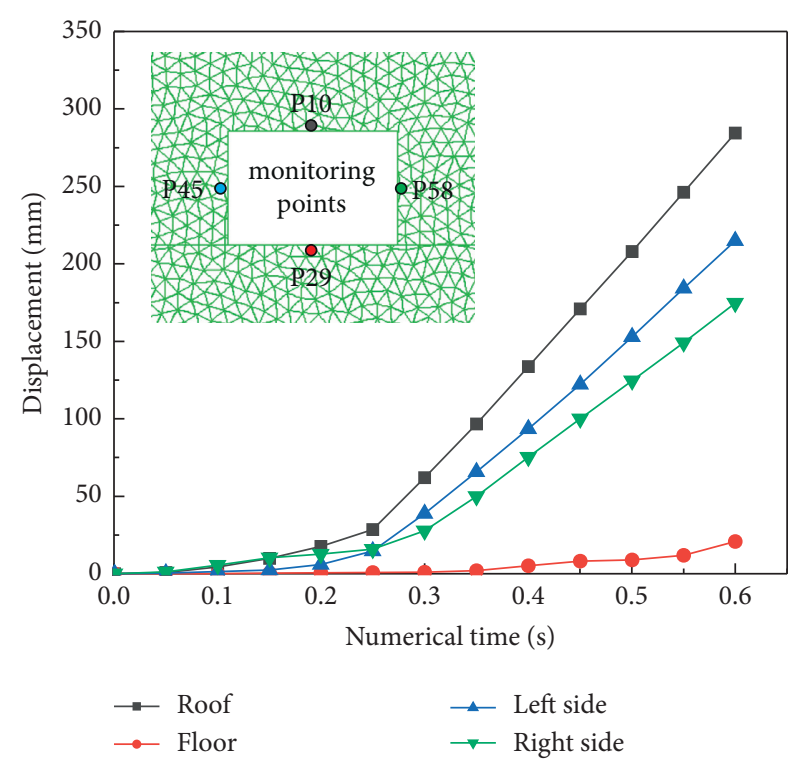

FIGURE 12: Simulated displacement curve of the surrounding rock.

was in high strength, and the stress concentration was released through the deformation of two ribs.

\section{The Support Scheme of Roadway Instability Induced by Mine Earthquake}

5.1. Support Scheme. As shown in Figure 13, four support schemes are adopted to reinforce the roadway:

Scheme 1: bolt-cable support.

Scheme 2: bolt-cable-mesh-shotcrete combined support.

Scheme 3: bolt-cable-mesh-steel strip- $\pi$-beam flexible support.

Scheme 4: scheme 3 + floor bolt support.

In UDEC, the "bolt-cable" is achieved by cable elements, and the "mesh-shotcrete" and "mesh + steel strip $+\pi$-beam" are performed by structure elements. The properties are shown in Tables 4 and 5 .

5.2. Stress Field of Disturbed Roadway. The maximum principal stress nephograms of disturbed roadway with different support schemes are illustrated in Figure 14. According to Figure 14, the stress-relaxed zone is significantly reduced after applying roadway support (compared with Figure 8), indicating that the surrounding rock could resist mine earthquake disturbance. In Figure 14(a), some spalling roof blocks can be observed, indicating that the roof caving was generated due to mine earthquake disturbance after the roadway was reinforced by the bolt-cable in scheme 1 . This would be dangerous to workers and machines. In Figure 14(b), the stress-relaxed zone in the floor expanded, below where the stress concentration was aggravated. The reason was that the combined support in scheme 2 belonged to a rigid support, which was not conducive to the stress release from surrounding rock deformation, resulting in the stress concentration in the floor. Therefore, the rigid support in the roadway 


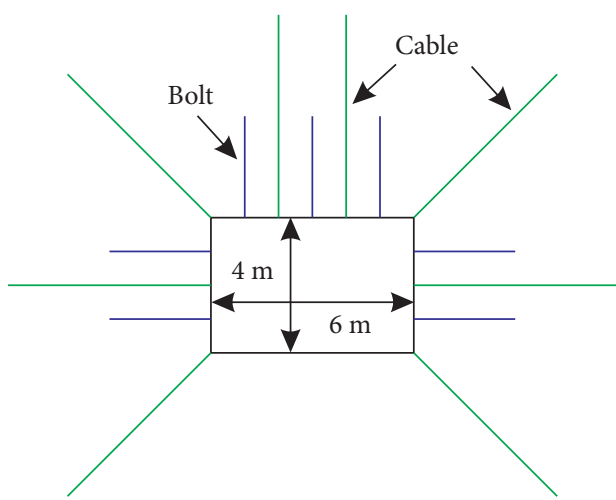

(a)

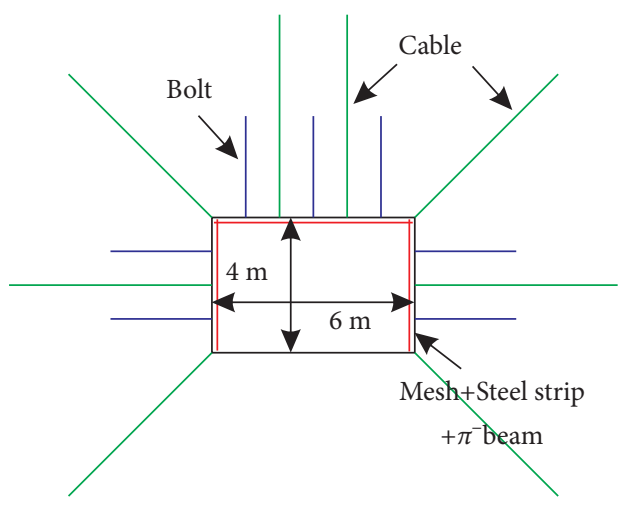

(c)

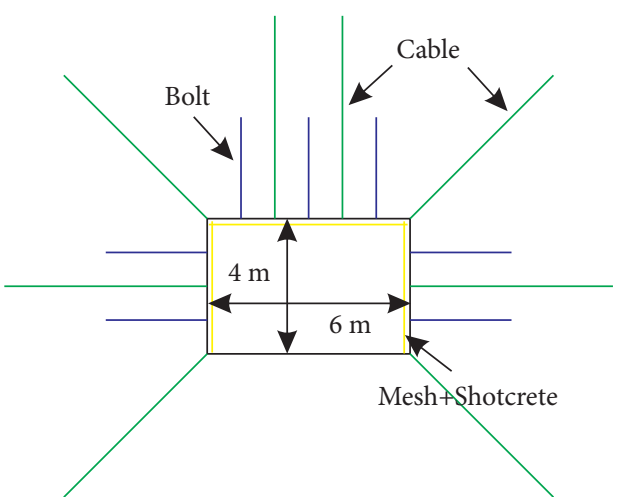

(b)

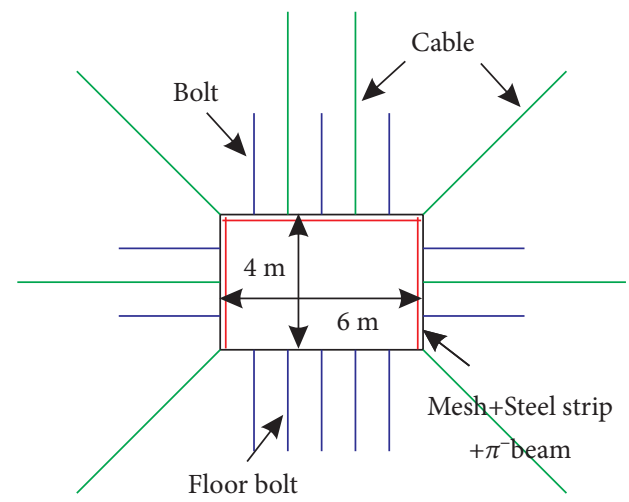

(d)

Figure 13: Four support schemes to reinforce the roadway.

Table 4: Properties of the bolt and cable elements used in the UDEC.

\begin{tabular}{lcccccc}
\hline Parameters & Density $\left(\mathrm{kg} / \mathrm{m}^{3}\right)$ & Elastic modulus $(\mathrm{GPa})$ & Tensile capability $(\mathrm{kN})$ & Bond stiffness $(\mathrm{N} / \mathrm{m} / \mathrm{m})$ & $\begin{array}{c}\text { Bond strength } \\
(\mathrm{N} / \mathrm{m})\end{array}$ & Pretension $(\mathrm{kN})$ \\
\hline Cable & 7500 & 200 & 480 & $2 \times 10^{9}$ & $4 \times 10^{5}$ & 280 \\
Bolt & 7500 & 200 & 120 & $2 \times 10^{9}$ & $4 \times 10^{5}$ & 80 \\
\hline
\end{tabular}

TABle 5: Properties of the structure elements in the UDEC.

\begin{tabular}{lccccc}
\hline Parameters & $\begin{array}{c}\text { Elastic modulus } \\
(\mathrm{GPa})\end{array}$ & $\begin{array}{c}\text { Compressive strength } \\
(\mathrm{MPa})\end{array}$ & $\begin{array}{c}\text { Tensile strength } \\
(\mathrm{MPa})\end{array}$ & $\begin{array}{c}\text { Contact normal stiffness } \\
(\mathrm{GPa} / \mathrm{m})\end{array}$ & $\begin{array}{c}\text { Contact shear stiffness } \\
(\mathrm{GPa} / \mathrm{m})\end{array}$ \\
\hline $\begin{array}{l}\text { Combined } \\
\text { support }\end{array}$ & 35 & 150 & 100 & 20 & 20 \\
Flexible support & 200 & 40 & 40 & 4 & 4 \\
\hline
\end{tabular}

led to the decrease of floor strength. In Figure 14(c), the stability and strength of the roadway were improved. However, there was an apparent stress-relaxed zone in the floor, affecting the operation of work equipment. In Figure 14(d), the stress-relaxed zone in the floor disappeared after the application of the floor bolt. The stress-relaxed zone in the rib also reduced to a certain extent, indicating that the overlying load was transmitted to the deep surrounding rock after the application of the floor bolt. The measurement was effectively improving the bearing capacity of the floor and the integrity of the support system. Therefore, from the perspective of the stress field, scheme 4 was conducive to improving the resistance to mine earthquake disturbance for the roadway.
5.3. Crack Field of Disturbed Roadway. The mesoscopic reinforcement mechanism of different support schemes on the roadway was studied through the crack distribution development to find the optimal scheme for dealing with the mine earthquake disturbance. The crack distributions in the roadway with different support schemes are shown in Figure 15. In the near-field surrounding rock, the tensile crack accounted for the largest proportion, while in the farfield surrounding rock, the shear crack accounted for the most significant proportion. The bolt-cable had a good reinforcement effect on the near-field surrounding rock due to the tensile-resistant ability. In Figure 15(a), the cracks in surrounding rock significantly reduced (compared with 


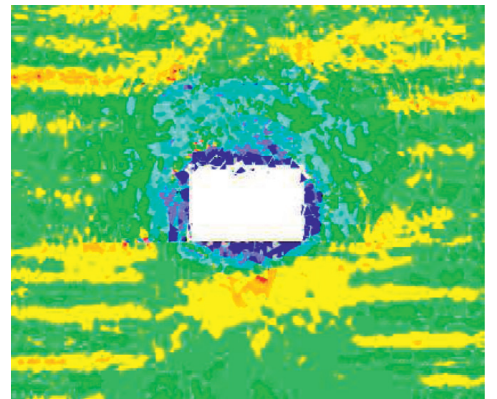

(a)

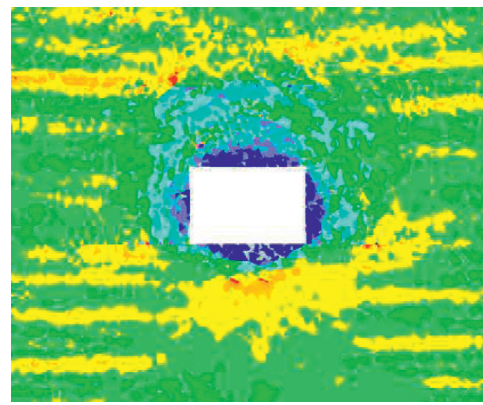

(c)

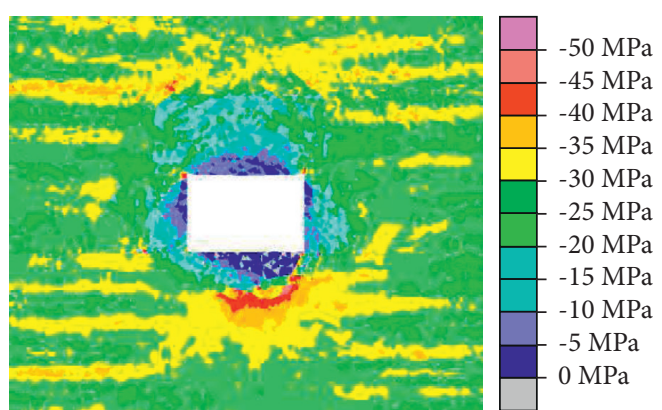

(b)

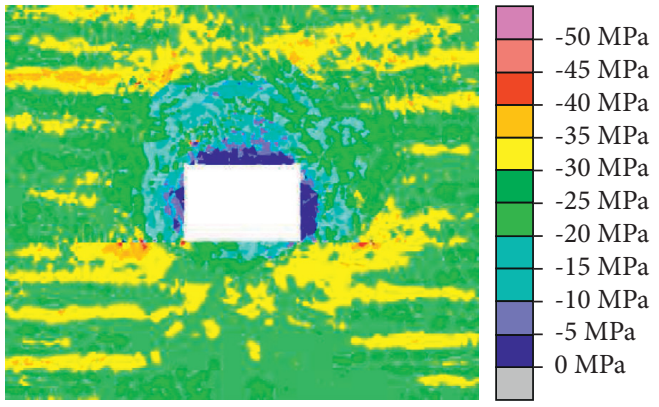

(d)

Figure 14: Maximum principal stress of RSR with different support schemes. (a) Scheme 1. (b) Scheme 2. (c) Scheme 3. (d) Scheme 4.

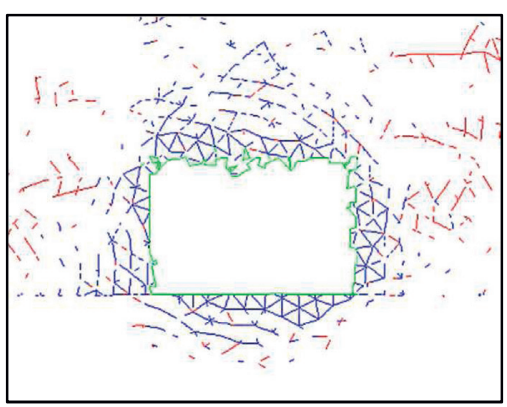

(a)

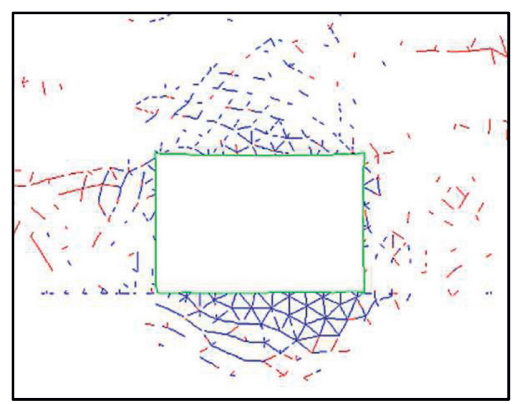

(b)

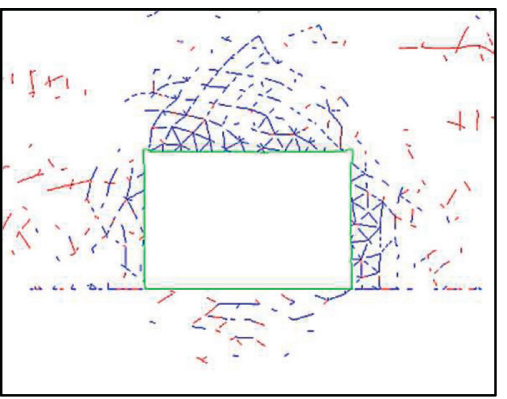

(d)

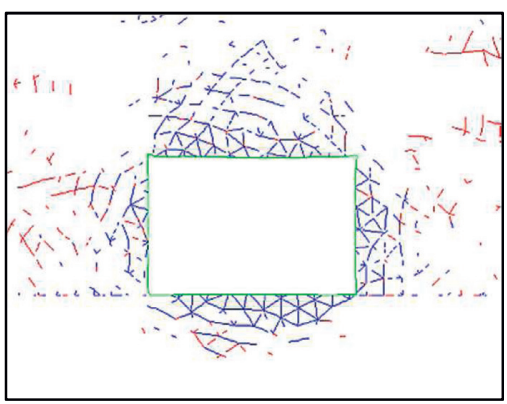

(c)

FIGURE 15: Crack distribution of roadway with different support schemes (red is the shear crack, blue is the tensile crack). (a) Scheme 1. (b) Scheme 2. (c) Scheme 3. (d) Scheme 4.

Figure 9) after applying scheme 1, but the blocks in the roof caved. A number of tensile cracks were generated in the floor, indicating that the bolt-cable had a good reinforcement effect on local areas rather than the whole body of the roadway. In Figure 15(b), after applying scheme 2, the number of cracks in the roof and rib was significantly reduced compared with scheme 1, indicating that the combined support effectively controlled the damage in rib and roof, enhancing the rock structure integrity. Simultaneously, an amount of elastic energy was accumulated in the roof and rib, which aggravated the impact instability dangerous. A large number of cracks generated in the floor 
created the condition for floor heave. In Figure 15(c), some cracks were developed in the roof and rib after applying scheme 3, forming the attenuation buffer for the mine earthquake energy, reducing the stress concentration degree. In addition, the roof caving did not occur. However, some cracks in the floor were not conducive to stability. In Figure 15(d), after adopting scheme 4, the attenuation zone was formed for mine earthquake energy in roof and rib, and the cracks in floor disappeared narrowly, indicating that the scheme "flexible support + floor bolt" was conducive to improving the integrity and stability of the roadway. Therefore, from the perspective of the displacement field, scheme 4 was the best to resist mine earthquake disturbance.

5.4. Displacement Field of Disturbed Roadway. The control effect of different support schemes on roadway deformation was obtained by analyzing the displacement field of the disturbed roadway. By setting monitoring lines around the roadway by FISH code, the displacement field was obtained, as illustrated in Figure 16.

After adopting scheme 1, the displacements of some monitoring points in the roof and ribs were much larger than those after adopting the combined support and the flexible support. The reason was that the lack of lining elements in the roof and ribs led to local caving. It showed that the bolt-cable was only effective for reinforcing surrounding rock within the bolted zone, failing to improve the integrity of surrounding rock. Therefore, only applying bolt-cable was not enough to resist the mine earthquake disturbance.

After adopting scheme 2, the displacements in the roof and ribs were tiny, indicating that the combined support had a good effect on controlling the deformation in the roof and rib. However, the displacement of the floor was relatively large due to the rigid support, which was not conducive to the release of the concentrated load in the roof and ribs. The stress concentration in ribs had to extrude and bend effect on the floor, resulting in serious floor heave phenomenon. Therefore, the combined support aggravated the damage in the floor caused by the mine earthquake disturbance.

After using scheme 3, the displacements in roof and ribs were slightly larger than those after adopting scheme 2, indicating that the flexible support had a control effect on the deformation in the roof and rib. Meanwhile, it allowed some degree of deformation in the roof and rib, conducive to releasing the elastic energy in surrounding rock and forming a buffer zone for mine earthquake energy. Combining scheme 3 and floor bolt, the displacement in roof and rib decreased to some extent, and the displacement in the floor was close to 0 . This indicates that the floor bolt is conducive to improving the overall stability. Therefore, from the perspective of the displacement field, scheme 4 was beneficial to resist mine earthquake disturbance for the roadway.

Due to the existence of joint cracks, damping characteristics, plastic deformation, and other factors in the rock mass, part of the energy carried by mine earthquake will dissipate through the propagation of stress waves, rock fracture, and joint slip. This part of the energy has an important influence on the transmission and attenuation characteristics of mine earthquake and directly affects the effect of mine earthquake. The greater the energy released by the system is, the greater the influence of the mine earthquake on the roadway is. Therefore, the FISH code is used to monitor the energy released by the system and the strain energy of the material under the disturbance of the mine earthquake and to study the change characteristics of the energy release and accumulation of the roadway surrounding rock with nonsupport, rigid support, and flexible support, respectively.

As can be seen from Figure 17(a), the energy released by the system is about $1.8 \times 10^{7} \mathrm{~J}$ when the roadway with nonsupport is disturbed by the mine earthquake and about $1.5 \times 10^{7} \mathrm{~J}$ when the rigid support and flexible support are adopted. With nonsupport, the energy of the system is more likely to be released along with the instability impact of the roadway. As can be seen from Figure 17(b), the peak value of material strain energy stored in the system is $8.8 \times 10^{6} \mathrm{~J}$ with nonsupport, $1.1 \times 10^{7} \mathrm{~J}$ with rigid support, and $1.0 \times 10^{7} \mathrm{~J}$ with flexible support, respectively. It shows that the roadway is prone to deformation and failure due to the mine earthquake disturbance, resulting in energy release. When the rigid support is adopted, more energy can be stored in the rock mass because the deformation of the rigid support is not easy to occur. When adopting flexible support, due to its characteristic that allows the roadway surrounding rock to produce certain deformation, it can absorb part of the energy of the mine earthquake and maintain the stability of the roadway surrounding rock.

Therefore, when the roadway surrounding rock is disturbed by the mine earthquake, the flexible support can reduce the accumulation of energy and has a good support effect.

As discussed above, only applying bolt-cable in roof and rib slowed down the stress reduction, improved the selfsustained ability, reduced the number of cracks in the nearfield zone, and decreased the displacement. However, some blocks caved in the roof. On this basis, adding mesh would avoid the floor caving phenomenon. By using the shotcrete, it became rigid support due to the high stiffness and high strength of shotcrete. Although the overall strength of the roof and ribs was improved, it caused a large accumulation of elastic energy and was not conducive to the release of mine earthquake energy. Based on bolt-cable-mesh, the steel strip- $\pi$-beam support was added to form flexible support, which successfully controlled the stability of surrounding rock. It allowed certain deformations in the roof and ribs, which was beneficial to release the elastic energy in surrounding rock and form a buffer zone for mine earthquake energy. On the basis, adding floor bolt, the cracks and deformation in the floor were reduced, and the stability in the roof and ribs was improved. Finally, the optimal support scheme "bolt-cable-mesh-steel strip- $\pi$-beam + bolt floor" for the roadway to resist mine earthquake disturbance was successfully proposed.

According to the field photos of the 1305 working face in Zhaolou Coal Mine damaged by the rockburst in Figure 3, serious roof caving and roadway deformation still occurred in the field with the support of "bolt + cable + mesh + 


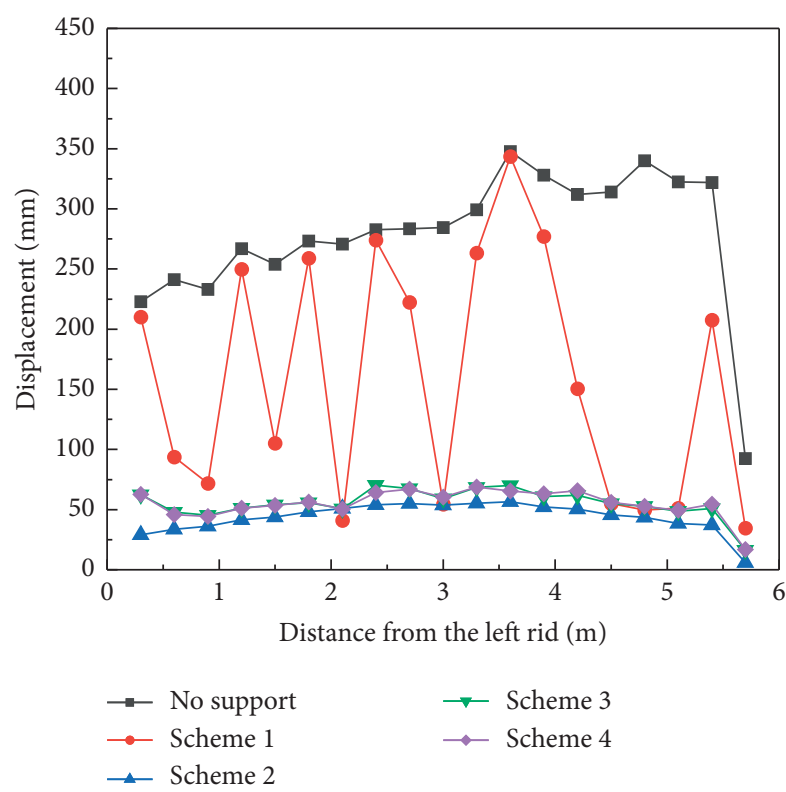

(a)

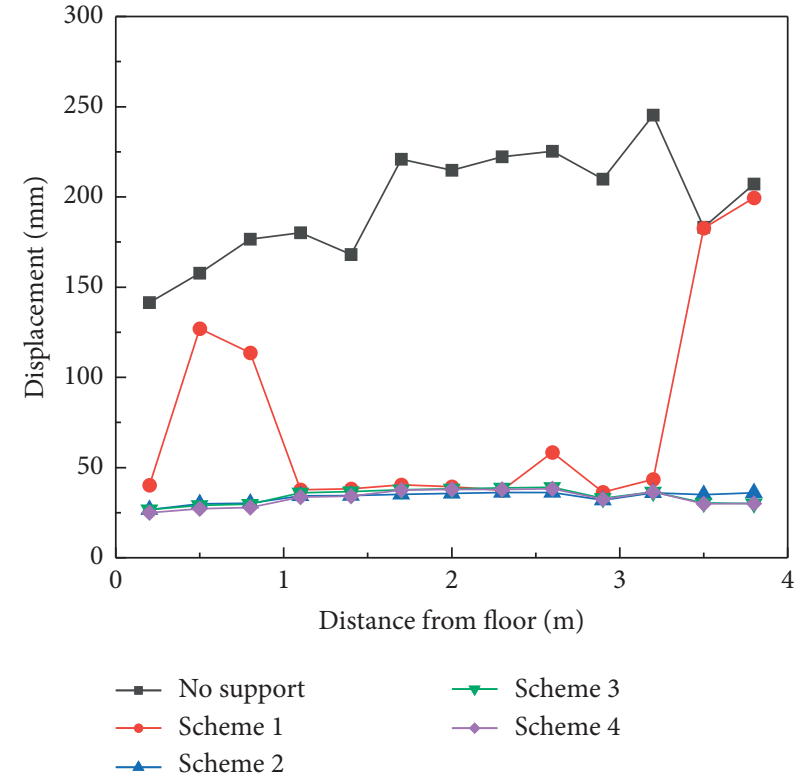

(b)

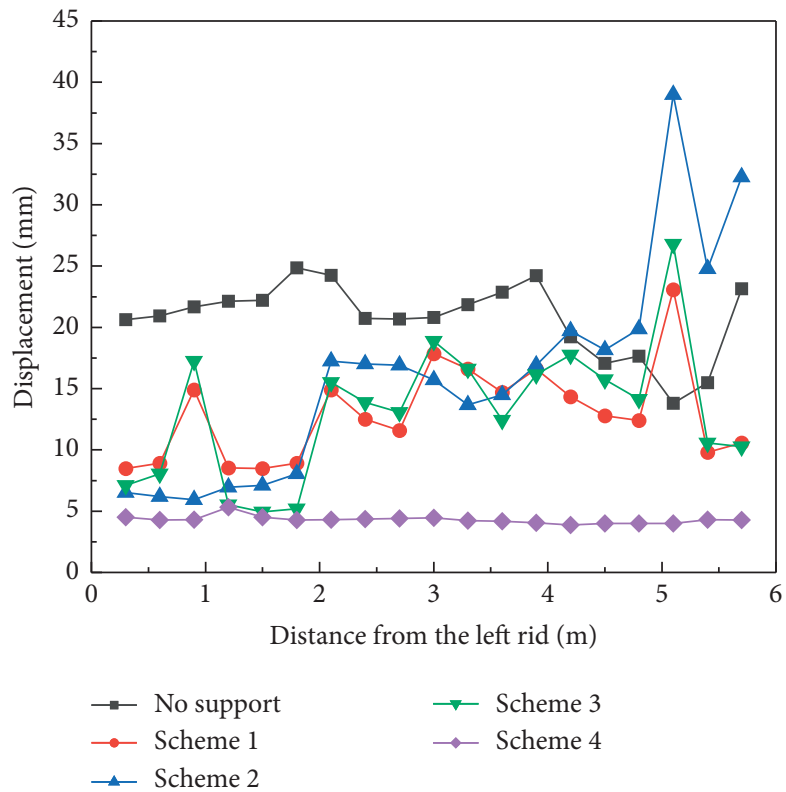

(c)

Figure 16: Displacement of roadway with different support schemes. (a) Roof. (b) Rib. (c) Floor.

shotcrete + hydraulic support," which could not cope with the rockburst well. Due to its strong rigidity, once the rockburst exceeds the limit of its bearing capacity, large-scale damage will occur. Therefore, it is believed that the scheme in this paper has a great guiding significance to solve the problem of the 1305 working face and similar working conditions to deal with the rockburst.

\section{Discussion}

In literature [23], the authors utilized PFC code to study the mechanism of roof caving resulted from mine earthquake disturbance under the support of bolt and cable and proposed the support scheme "strengthening integrity surrounding rock + bolt + cable," which was similar to scheme 4 in this paper. However, in his study, the cable was mainly shear-resistant and a large number of particles collapsed near it, which made it fail to embody the tensileresistant. In this paper, the shear- and tensile-resistant properties of the bolt and cable were embodied simultaneously after the rock block was anchored by bolt and cable. Afterward, only utilizing cable could not prevent the small block caving caused by tensile crack propagation. Applying mesh could absorb part of the impact energy and slow down the speed of roof caving to reduce the occurrence of roof caving when the mine earthquake with 

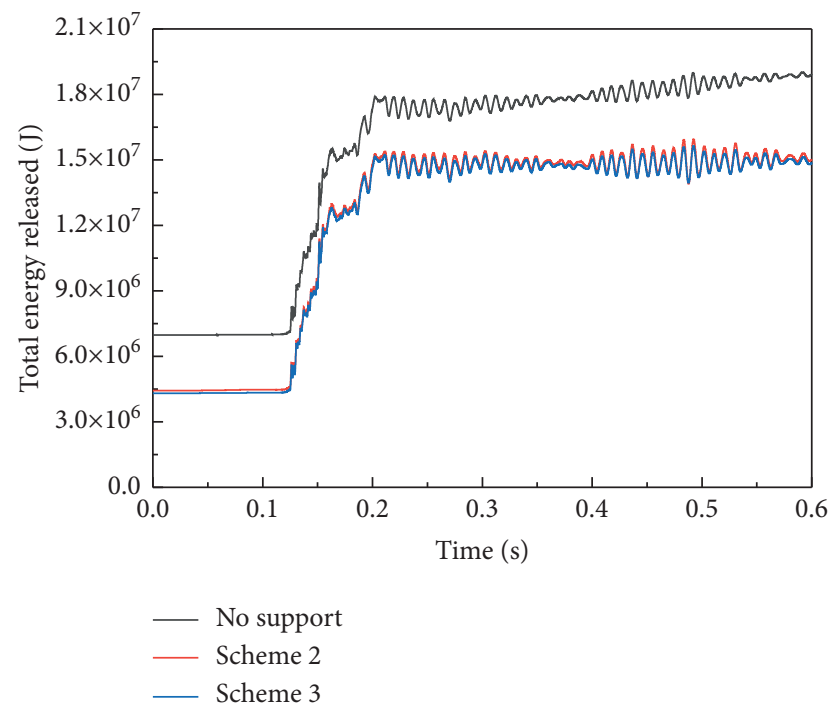

(a)

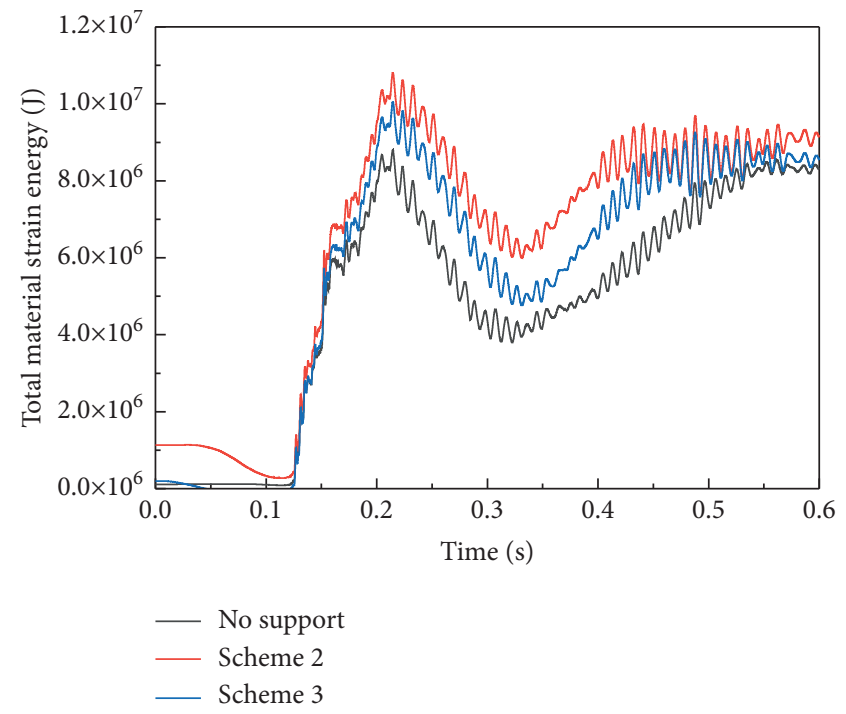

(b)

FIgURE 17: Energy of roadway with different support schemes. (a) Total energy released. (b) Total material strain energy.

small energy occurred. But the mesh failed to deal with the mine earthquake with large energy. According to literature [27-29], the rigid support played a good role in the case of mine earthquake with small energy through preventing the deformation and crack propagation of surrounding rock. However, we found that the mine earthquake with large energy caused severe stress concentration and floor heave phenomenon. The phenomenon was caused by the failure to form the buffer zone due to its strong rigidity with small allowable deformation. Adopting the flexible support [30-32], the buffer zone was founded to avoid stress concentration due to its deformation, which was suitable to manage all mine earthquakes. Because of the floor heave phenomenon, according to literature [33], this paper put forward the support scheme "floor bolt" to control the deformation of the floor. It is found that the scheme could effectively control the initiation and expansion of floor cracks, transfer the stress concentration phenomenon from the superficial layer to the deep layer of the surrounding rock, and improve the integrality and stability of the roadway. The support scheme "bolt-cable-mesh-steel strip- $\pi$-beam + floor bolt" proposed in this paper had a great effect on preventing roadway impact instability caused by mine earthquake disturbance.

\section{Conclusions}

Based on the background of the 1305 working face in the Zhaolou Coal Mine, this paper studied the characteristics of roadway impact instability induced by mine earthquake disturbance from the aspects of stress field, crack field, displacement field, and energy field. The corresponding optimal support scheme was proposed.

(1) The greater the amplitude of mine earthquake disturbance was, the more the dynamic energy involved in the damage of coal-rock mass was and the more severe the destruction of roadway was. The upper hypocenter had the most expansive influence on the roadway, followed by the left hypocenter. The bottom hypocenter had a relatively small influence. The hypocenter located in the upper zone was the focus of research.

(2) The superposition of the dynamic stress caused by the far-field mine earthquake and the high static stress induced the impact failure of coal-rock mass around the roadway, resulting in severe roof subsidence, rib heave, and bottom heave. The evolution of tensile cracks caused the severe impact failure of roadway from a mesoscopic perspective. There was a coupling relationship between the stress-relaxed zone and the crack propagation zone of the roadway.

(3) Only the application of bolt-cable in roof and rib strengthened the ability to resist mine earthquake in aspects of stress, cracks, and deformation, though some blocks caved in roof. The problem can be avoided by adopting "mesh." The shotcrete caused the accumulation of elastic energy and the difficulty of releasing mine earthquake energy due to the rigid support. Applying the steel strip- $\pi$-beam support allowed certain deformations in the roof and ribs, which was beneficial to release the elastic energy and mine earthquake energy due to flexible support.

(4) By introducing the floor bolt, the cracks and deformation in the floor were reduced, and the stability in the roof and ribs was improved. The optimal support scheme "bolt-cable-mesh-steel strip$\pi$-beam + bolt floor" for the roadway to resist mine earthquake disturbance is successfully proposed, which has particular guiding significance for the support of coal mine roadway. 


\section{Data Availability}

The data used to support the findings of this study are included within the article.

\section{Conflicts of Interest}

The authors declare that they have no conflicts of interest.

\section{Acknowledgments}

The authors gratefully wish to acknowledge the Natural Science Foundation of Zhejiang Province (LQ20E040002 and LQ21D020001) and the National Natural Science Foundation of China (42107177 and 42002275).

\section{References}

[1] H. Kang, "Sixty years development and prospects of rock bolting technology for underground coal mine roadways," Journal of China University of Mining \& Technology, vol. 45, no. 6, pp. 1071-1081, 2016.

[2] H. Xie, "Research review of the state key research development program of China: deep rock mechanics and mining theory," Journal of China Coal Society, vol. 44, no. 5, pp. 1283-1305, 2019.

[3] M. He, H. Xie, S. Peng, and Y. Jiang, "Study on rock mechanics in deep mining engineering," Chinese Journal of Rock Mechanics and Engineering, vol. 4, no. 16, pp. 2803-2813, 2005.

[4] Y. Jiang, Y. Pan, F. Jiang, and L. Dou, "State of the art review on mechanism and prevention of coal bumps in China," Journal of China Coal Society, vol. 39, no. 2, pp. 205-213, 2014.

[5] F. Jiang, Q. Wei, C. Wang, and S. Yau, "Analysis of rock burst mechanism in extra-thick coal seam controlled by huge thick conglomerate and thrust fault," Journal of China Coal Society, vol. 39, no. 7, pp. 1191-1196, 2014.

[6] Y.-s. Pan, X.-f. Lü, Z.-h. Li, and S. Dai, "Experimental study of dynamic failure process of roadway under high velocity impact loading," Chinese Journal of Rock Mechanics and Engineering, vol. 32, no. 5, pp. 1281-1286, 2011.

[7] A. Cao, J. Fan, Z. Mu, and X. Guo, "Burst failure effect of mining-induced tremor on roadway surrounding rock," Journal of China Coal Society, vol. 35, no. 12, pp. 2006-2010, 2010.

[8] H.-p. Xie and W. G. Pariseau, "Fractal character and mechanism of rock bursts," Chinese Journal of Rock Mechanics and Engineering, vol. 12, no. 1, pp. 28-37, 1993.

[9] M. Gao, Y. Zhao, and Y. We, "Stress and energy criterion of the roadway destruction subjected to disturbance type rockburst and its practice," Journal of China Coal Society, vol. 41, no. 4, pp. 808-814, 2016.

[10] X. P. Zhou, Q. H. Qian, and H. Q. Yang, "Rock burst of deep circular tunnels surrounded by weakened rock mass with cracks," Theoretical and Applied Fracture Mechanics, vol. 56, no. 2, pp. 79-88, 2011.

[11] B. Fan, F. Zhao, B. Wang, Q. Wu, and Z. Zhang, "Rockburst occurrence mechanism based on the self-sustaining timevarying structure of surrounding rock," Shock and Vibration, vol. 2020, Article ID 8864336, 13 pages, 2020.

[12] L. Dou, J. He, A. Cao, and S. Gong, "Rock burst prevention methods based on theory of dynamic and static combined load induced in coal mine," Journal of China Coal Society, vol. 40, no. 7, pp. 1469-1476, 2015.

[13] X. Liu, S. Song, Y. Tan et al., "Similar simulation study on the deformation and failure of surrounding rock of a large section chamber group under dynamic loading," International Journal of Mining Science and Technology, vol. 31, no. 3, pp. 495-505, 2021.

[14] X. Hao, W. Du, Y. Zhao et al., "Dynamic tensile behaviour and crack propagation of coal under coupled static-dynamic loading," International Journal of Mining Science and Technology, vol. 30, no. 5, pp. 659-668, 2020.

[15] Y. X. Xiao, X. T. Feng, S. J. Li, G. L. Feng, and Y. Yu, "Rock mass failure mechanisms during the evolution process of rockbursts in tunnels," International Journal of Rock Mechanics and Mining Sciences, vol. 83, pp. 174-181, 2016.

[16] X. Li and L. Weng, "Numerical investigation on fracturing behaviors of deep-buried opening under dynamic disturbance," Tunnelling and Underground Space Technology, vol. 54, no. 4, pp. 61-72, 2016.

[17] K. K. Panthi, "Evaluation of rock bursting phenomena in a tunnel in the Himalayas," Bulletin of Engineering Geology and the Environment, vol. 71, no. 4, pp. 761-769, 2012.

[18] W. C. Zhu, Z. H. Li, L. Zhu, and C. A. Tang, "Numerical simulation on rockburst of underground opening triggered by dynamic disturbance," Tunnelling and Underground Space Technology, vol. 25, no. 5, pp. 587-599, 2010.

[19] G. Liu, Z. Mu, J. Atif, G. Shaokun, Y. Jing, and C. Jinglong, "Investigation into mechanism of floor dynamic rupture by evolution characteristics of stress and mine tremors: a case study in guojiahe coal mine, China," Shock and Vibration, vol. 2018, Article ID 3279036, 13 pages, 2018.

[20] X.-s. Liu, D.-y. Fan, and Y.-1. Tan, "Failure evolution and instability mechanism of surrounding rock for close-distance chambers with super-large section in deep coal mines," International Journal of Geomechanics, vol. 21, no. 5, Article ID 04021049, 2021.

[21] X. Liu, D. Fan, Y. Tan et al., "New detecting method on the connecting fractured zone above the coal face and a case study," Rock Mechanics and Rock Engineering, vol. 54, pp. 4379-4391, 2021.

[22] H. Kang, "Support technologies for deep and complex roadways in underground coal mines: a review," International Journal of Coal Science \& Technology, vol. 1, no. 3, pp. 261-277, 2014.

[23] H. Jing, J. Wu, Q. Yin, S. Xinshuai, and Z. Zhenlong, "Particle flow simulation of rock burst and roof fall of deep coal roadway under dynamic disturbance," Chinese Journal of Rock Mechanics and Engineering, vol. 39, no. S2, pp. 3475-3487, 2020.

[24] Z. Xiao, J. Liu, S. Gu et al., "A control method of rock burst for dynamic roadway floor in deep mining mine," Shock and Vibration, vol. 2019, Article ID 7938491, 16 pages, 2019.

[25] G. Wang, S. Gong, L. Dou, G. Li, W. Cai, and C. Fan, "A novel experimental technique to simulate shock behaviour and bursting failure of roadways," Shock and Vibration, vol. 2019, Article ID 9395354, 13 pages, 2019.

[26] S. Su, Y. Du, J. Zhu, L. Zhang, Z. Zhao, and B. Meng, "Numerical study on bearing behavior of layered rock mass for deep roadway," Journal of Mining and Strata Control Engineering (China), vol. 2, no. 1, pp. 52-62, Article ID 013002, 2020.

[27] S. C. Li, Q. Wang, H. T. Wang et al., "Model test study on surrounding rock deformation and failure mechanisms of 
deep roadways with thick top coal," Tunnelling and Underground Space Technology, vol. 47, pp. 52-63, 2015.

[28] W. Yu, W. Wang, X. Chen, and S. Du, "Field investigations of high stress soft surrounding rocks and deformation control," Journal of Rock Mechanics and Geotechnical Engineering, vol. 7, no. 4, pp. 421-433, 2015.

[29] S. Yang, M. Chen, H. Jing, K. Chen, and B. Meng, "A case study on large deformation failure mechanism of deep soft rock roadway in Xin' an coal mine, China," Engineering Geology, vol. 217, pp. 89-101, 2016.

[30] K. K. Peter and M. Cai, "Design of rock support system under rockburst condition," Journal of Rock Mechanics and Geotechnical Engineering, vol. 4, no. 3, pp. 215-227, 2012.

[31] X. Yang, E. Wang, and X. Ma, "A case study on optimization and control techniques for entry stability in non-pillar longwall mining," Energies, vol. 12, no. 3, 2019.

[32] Y.-Y. Jiao, L. Song, X.-Z. Wang, and A. Coffi Adoko, "Improvement of the U-shaped steel sets for supporting the roadways in loose thick coal seam," International Journal of Rock Mechanics and Mining Sciences, vol. 60, pp. 19-25, 2013.

[33] X. Sun, D. Wang, J. Feng, C. Zhang, and Y. Chen, "Deformation control of asymmetric floor heave in a deep rock roadway: a case study," International Journal of Mining Science and Technology, vol. 24, no. 6, pp. 799-804, 2014.

[34] Itasca Consulting Group Ltd, User Manual of UDEC Code, Itasca Consulting Group Ltd., Minneapolis, USA, 2011.

[35] S. Zhong, Q. Jiang, C. Liu, and S. Li, "In-site core disking phenomenon and break mechanism of hard marble: investigation in $2400 \mathrm{~m}$ deep-buried underground laboratory," Journal of Central South University, vol. 27, no. 10, 2020.

[36] Q. Jiang, X. Liu, F. Yan, D. Xu, and G. Feng, "Failure performance of $3 \mathrm{dp}$ physical twin-tunnel model and corresponding safety factor evaluation," Rock Mechanics and Rock Engineering, vol. 6, pp. 1-20, 2020.

[37] X. Xiang, J. Li, H. Li, and Y. Liu, "Udec modeling of vibration characteristics of jointed rock mass under explosion," Rock and Soil Mechanics, vol. 4, no. 1, pp. 50-56, 2005.

[38] J. He, Research of Mining Dynamic Loading Effect and its Induced Rock Burst in Coal Mine, Ph.D. thesis, China University of Mining and Technology, Xuzhou, China, 2013. 